\title{
Perioperative care after thoracoabdominal aortic aneurysm repair: The Baylor College of Medicine experience. Part 1: Preoperative considerations
}

Subhasis Chatterjee, MD, ${ }^{\mathrm{a}, \mathrm{b}}$ Jose G. Casar, MD, ${ }^{\mathrm{b}}$ Scott A. LeMaire, MD, ${ }^{\mathrm{b}, \mathrm{c}, \mathrm{d}}$ Ourania Preventza, MD, ${ }^{\mathrm{b}, \mathrm{c}, \mathrm{d}}$ and Joseph S. Coselli, MD $^{\mathrm{b}, \mathrm{c}, \mathrm{d}}$

$\longrightarrow$ Video clip is available online.

The Texas Medical Center has been home to pioneering aortic surgeons Michael E. DeBakey, Denton A. Cooley, and E. Stanley Crawford, on whose legacies modern thoracoabdominal aortic surgery has been built. During the past 3 decades, our single-center practice (led by J.S.C.) has performed more than 3600 open thoracoabdominal aortic aneurysm repairs (TAAARs), including the largest published series to date $(\mathrm{N}=3309){ }^{1}$

Continuing to refine the perioperative management of TAAAR patients is critical. In this 2-part series, we discuss the current practice at Baylor College of Medicine/CHI Baylor St Luke's Medical Center in Houston, Texas. Part 1 of this report focuses on unique preoperative considerations to reduce the risk of adverse operative outcomes. Part 2 focuses on postoperative management to reduce the risk of complications and to manage those that arise. Although other experienced centers may have different approaches to common conditions and produce good surgical outcomes, we provide this guide as a foundation for surgeons, intensivists, trainees, advanced practice providers, nurses, and others involved in the multidisciplinary management of these complex surgical patients.

\section{PREOPERATIVE CONSIDERATIONS}

We have described our approach to preoperative planning in detail. ${ }^{2}$ Briefly, we assess age and physiologic reserve,

\footnotetext{
From the Divisions of ${ }^{\mathrm{a} G e n e r a l ~ S u r g e r y ~ a n d ~}{ }^{\mathrm{b}}$ Cardiothoracic Surgery, Michael E. DeBakey Department of Surgery, Baylor College of Medicine; ${ }^{\mathrm{c}}$ Department of Cardiovascular Surgery, Texas Heart Institute; and ${ }^{\mathrm{d}}$ Department of Cardiovascular Surgery, CHI St Luke's Health—Baylor St Luke's Medical Center, Houston, Tex. Dr LeMaire's work is partially supported by the Jimmy and Roberta Howell Professorship in Cardiovascular Surgery at Baylor College of Medicine.

Received for publication Aug 26, 2019; revisions received Nov 1, 2019; accepted for publication Nov 21, 2019; available ahead of print Feb 19, 2020

Address for reprints: Subhasis Chatterjee, MD, One Baylor Plaza, BCM390, Houston, TX 77030 (E-mail: Subhasis.Chatterjee@bcm.edu).

J Thorac Cardiovasc Surg 2021;161:693-8

0022-5223/\$36.00

Copyright (c) 2020 by The American Association for Thoracic Surgery

https://doi.org/10.1016/j.jtcvs.2019.11.142
}

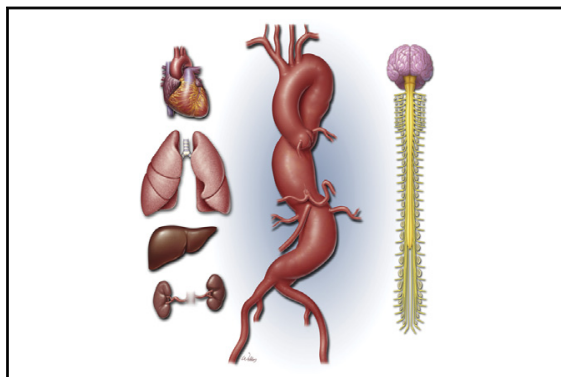

Multiple organ systems must be optimized before thoracoabdominal aortic aneurysm repair.

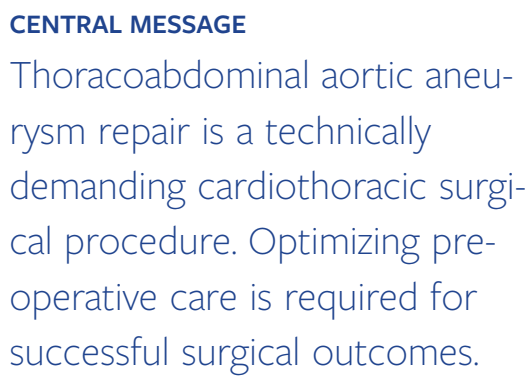

stratify risk, stop antiplatelet and anticoagulant medications, advise tobacco cessation, and optimize major neurologic, cardiovascular, respiratory, and renal comorbidities. ${ }^{3}$ The major surgical risks include mortality, paraplegia, renal failure, stroke, respiratory failure, and myocardial infarction. Each of these risks is discussed with the patient and family. Surgical timing is influenced by aneurysm size and growth rate; presence of leak, rupture, or acute dissection; and symptomatology (Table 1$){ }^{2}$

\section{Neurologic}

In our experience, approximately $10 \%$ of patients who present for TAAAR have had a previous stroke. ${ }^{1}$ For these patients and those with neurologic symptoms, a routine surveillance computed tomography (CT) scan of the head is performed, and preoperative neurology consultation is obtained if needed. In patients with preexisting neurologic deficit, functional status should be evaluated before proceeding with surgery.

Carotid duplex ultrasonography is routinely used to evaluate for concomitant carotid artery disease in patients older 
TABLE 1. Summary: preoperative considerations

\begin{tabular}{lll}
\hline Organ/system & \multicolumn{1}{c}{ Assessment } & \multicolumn{1}{c}{ Diagnostic considerations } \\
\hline Neurologic & Previous stroke & CT scan of the head \\
Cerebrovascular & Carotid artery stenosis & Duplex carotid ultrasonography \\
General aortic & Proximal aortic disease & CT scan, echocardiography \\
Cardiovascular & Presence and/or extent of coronary artery disease & Electrocardiography* \\
& & $\begin{array}{l}\text { Myocardial perfusion testing* } \\
\text { Coronary angiography* }\end{array}$ \\
& Cardiac function and valvular heart disease & Echocardiography
\end{tabular}

$C T$, Computed tomography; NOAC, non-vitamin $\mathrm{K}$ oral anticoagulants (dabigatran, rivaroxaban, apixaban, edoxaban). *As appropriate.

than 60 years of age. Although not reported in the literature for TAAA, the prevalence of asymptomatic carotid artery stenosis $>70 \%$ approaches $11 \%$ in patients with abdominal aortic aneurysm. ${ }^{4}$ Symptomatic carotid disease is treated before elective TAAAR. Hypothermic circulatory arrest, which we use in $1.5 \%$ of cases, ${ }^{1}$ can be complicated by asymptomatic high-grade carotid disease; further workup — and possibly carotid intervention — may be warranted preoperatively.

\section{General Aortic}

A diagram of the E. Stanley Crawford classification of the extent of TAAA is provided in Figure 1. In general, extent I and II patients present at a slightly younger age, mainly because of their greater prevalence of heritable thoracic aortic disorders and aortic dissection. In comparison, extent III and, especially, extent IV patients tend to be older, with a greater prevalence of atherosclerotic comorbidities, and demographically
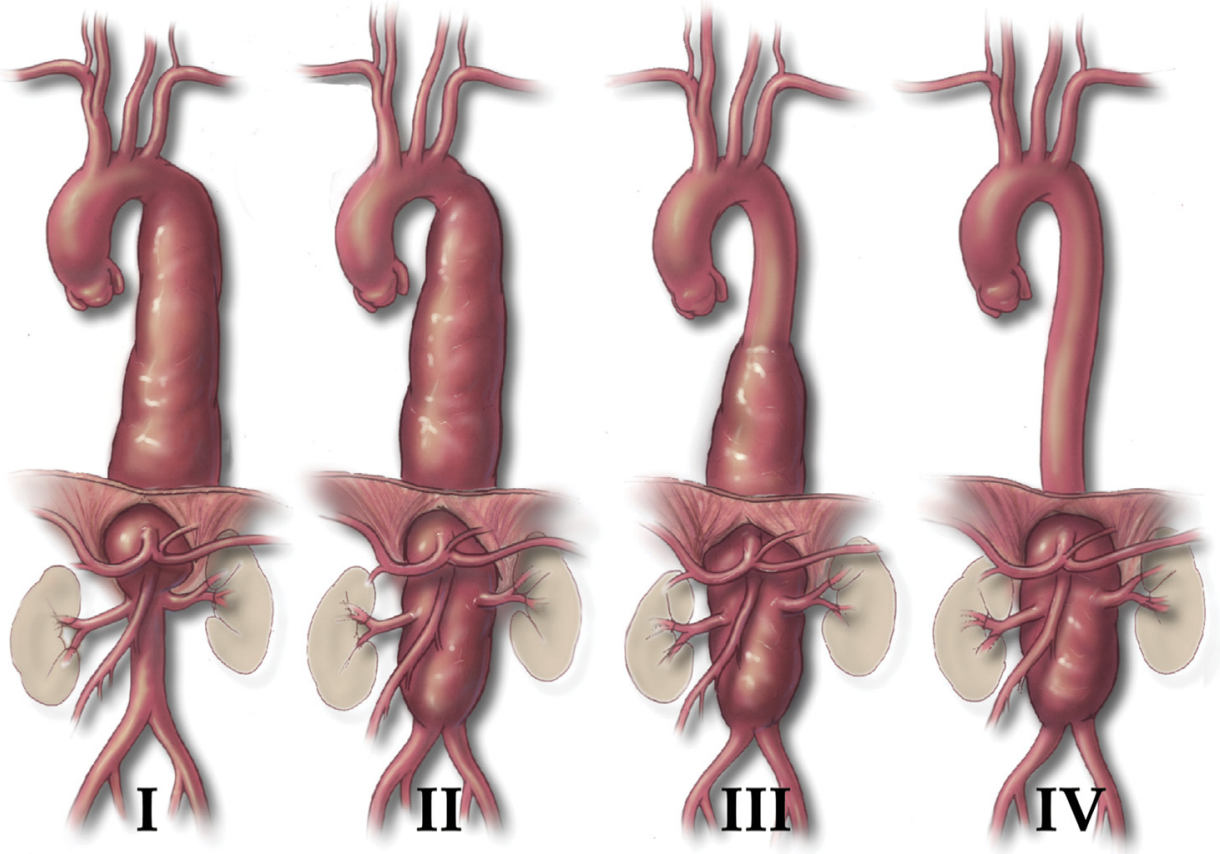

FIGURE 1. Crawford classification of the extent of thoracoabdominal aortic aneurysms. The risk of spinal cord deficit is greatest with extent II and III aneurysms. 
are more similar to patients with abdominal aortic aneurysm.

For patients who present with concomitant proximal aortic aneurysm larger than $5 \mathrm{~cm}$ and who have a connective tissue or heritable thoracic aortic disorder, surgery for the ascending aorta is performed first. If the aortopathy begins at the aortic root, then the aortic valve is either repaired or replaced, depending on the morphology of the valve, the age of the patient, and the patient's preference. For ascending aneurysms with a diameter between 4.5 and $5 \mathrm{~cm}$, we proceed with TAAAR first and watch the proximal aorta with interval imaging. However, if there is rapid growth ( $>3 \mathrm{~mm}$ annually), then strong consideration is given to proceeding with repair of the proximal aorta first.

Patients who present with an acute symptomatic TAAA and need urgent or emergency surgery are managed with anti-impulse therapy, including strict blood pressure control, to maintain a systolic blood pressure less than 110 to $120 \mathrm{~mm} \mathrm{Hg}$ and heart rate less than 70 beats per minute. Intravenous beta blockers (esmolol, labetalol) and vasodilators (nicardipine) are used while preoperative laboratory and diagnostic tests are expeditiously performed.

Marfan syndrome or another heritable thoracic aortic disease may be suspected in patients with characteristic phenotypic features or a familial history of sudden death. Appropriate referral to a genetic counselor is made postoperatively for patient and family screening and counseling. Patients presenting for reoperative TAAAR after previous distal aortic repair are at greater risk of requiring splenectomy; preoperative vaccination against Streptococcus pneumoniae, Hemophilus influenzae type B, and Neisseria meningitides should be considered.,

\section{Cardiovascular}

Preoperative cardiovascular assessment is important for risk stratification and reducing the patient's risk of cardiac complications. This assessment includes evaluating known coronary artery disease (CAD), which is present in approximately $30 \%$ of extent I and II patients and almost $50 \%$ of extent III and IV patients. ${ }^{1}$ In addition, cardiac assessment seeks to identify active CAD symptoms (unstable angina pectoris, stable angina, myocardial infarction within the previous 30 days) and other risk factors to determine a patient's ability to tolerate aortic crossclamping; the clampinduced immediate increase in afterload to the heart and resultant fluid shifts and blood loss can increase myocardial oxygen demand, leading to left ventricular (LV) distension and failure. This evaluation includes electrocardiography and myocardial perfusion testing. In addition, with cardiology consultation, we use selective coronary angiography for preexisting CAD in an individualized approach consistent with American College of Cardiology/American Heart Association guidelines. ${ }^{7}$
Another approach is routine coronary angiography, as described by Girardi and colleagues ${ }^{8}$ in a report of 592 patients presenting for TAAAR or descending thoracic aneurysm repair. In this series, $7 \%$ of patients required coronary artery bypass grafting $(\mathrm{CABG})$ for left main or 3 -vessel CAD before TAAAR. Another $9 \%$ of patients were found to have 1- or 2-vessel CAD and were treated with bare-metal stents and dual antiplatelet therapy (DAPT) for 4 to 6 weeks before undergoing elective TAAAR. Reassuringly, no patient treated with this approach had aneurysm rupture in the interval between stenting and TAAAR, the purpose of which is to allow bare-metal stent endothelialization.

We agree with this more aggressive approach to coronary revascularization because TAAAR is probably associated with greater hemodynamic stress than the surgical procedures on which the guidelines are based. We favor treating 1- or 2-vessel CAD with balloon angioplasty if TAAAR must be performed within the next 2 weeks, consistent with American Heart Association guidelines (Class I level of recommendation-Level of evidence C). ${ }^{7}$ For patients scheduled for elective TAAAR, 1- or 2-vessel CAD should be revascularized with bare-metal stent placement, followed by DAPT for 30 days (Class I level of recommendation-Level of evidence B). Although patients who have already received a drug-eluting stent are advised to wait for 1 year before DAPT is temporarily discontinued for surgery, it appears reasonable to temporarily stop DAPT at 6 months to proceed with surgery. ${ }^{7}$ Finally, for patients with 3-vessel or left main disease, CABG is recommended, and TAAAR is deferred until recovery, typically 2 to 3 months later. Each of these decisions is individualized with cardiology consultation and takes into account patient symptoms, TAAA size and growth rate, and comorbidities, balancing the risks associated with proceeding with surgery against the risks incurred by waiting.

In our experience, approximately $15 \%$ of patients have already had $\mathrm{CABG}^{1}$; extent I or II TAAAR (Figure 1) patients with a patent left internal thoracic artery graft from previous $\mathrm{CABG}$ may require left carotid-to-subclavian artery bypass preoperatively to prevent intraoperative myocardial ischemia due to proximal clamp placement. $^{9}$

In our practice, approximately $75 \%$ of patients are already taking beta blockers, and $50 \%$ are taking lipidlowering agents; both medications are continued until surgery. About $30 \%$ of patients are taking angiotensinconverting enzyme inhibitors, which are also continued until surgery, consistent with American Heart Association guidelines (IIA-B). ${ }^{7}$ Recent randomized trials do not suggest that discontinuing angiotensin-converting enzyme inhibitors before cardiac surgery provides any protection against the development of postoperative vasoplegic shock or increased need for vasopressors. ${ }^{10}$ 
Cardiovascular workup should also include echocardiographic screening for cardiac function and valvular heart disease. LV ejection fraction less than $30 \%$ to $35 \%$ is poorly tolerated during repair. Severe aortic or mitral valve regurgitation requires intervention before TAAAR; otherwise, crossclamping could lead to hemodynamic instability. Moderate valvular regurgitation is treated according to the patient's concomitant cardiac or proximal aortic surgical conditions and TAAAR urgency. Although this treatment typically involves surgical valve procedures performed via sternotomy, we have used transcatheter aortic and mitral valve therapies as well. In general, aortic crossclamping is not well tolerated in patients with moderate aortic regurgitation combined with decreased ejection fraction, significant LV hypertrophy, or small LV size; thus, valvular regurgitation should be corrected before TAAAR in these patients.

\section{Respiratory}

Pulmonary complications are the most common category of major postoperative complications after TAAAR, affecting $36 \%$ of patients. ${ }^{1}$ Chronic obstructive pulmonary disease and smoking are prevalent in this patient population; coupled with an incision involving both the thoracic and upper abdominal cavities, these factors place patients at high risk of pulmonary complications. Preoperative pulmonary assessment includes quantitative pulmonary function testing and arterial blood gas evaluation to determine whether the patient has sufficient respiratory reserve to tolerate single-lung ventilation, although no specific spirometry values reliably predict pulmonary complications. ${ }^{11}$ Patients with a forced expiratory volume in 1 second $>1.0 \mathrm{~L}$ and a partial pressure of carbon dioxide $<45 \mathrm{~mm} \mathrm{Hg}$ are suitable for TAAAR. ${ }^{12}$ In a propensitymatched comparison, a forced expiratory volume in 1 second $<50 \%$ doubled the risk of major adverse events. ${ }^{13}$

Patients with marginal pulmonary function are optimized with pulmonary rehabilitation for 1 to 3 months preoperatively. This rehabilitation includes exercise, weight loss, incentive spirometry training, bronchodilator therapy, and mandatory tobacco cessation for at least 4 weeks. If preoperative pulmonary infection or bronchospasm is suspected, then appropriate treatment before surgery is advised for these conditions. Patients with marginal pulmonary function and hypercarbia are carefully evaluated with attention to other comorbidities, age, and frailty to determine whether the surgical risk is prohibitive.

Patients with extent I or II TAAA or who have had previous aortic arch surgery should be examined for voice quality. Hoarseness or abnormal voice quality should be evaluated by direct laryngoscopy to document the status of the vocal cords. We would not advise intervening on preoperative right vocal cord dysfunction before TAAAR because of concern that the double-lumen endotracheal tube (ETT) placed at the time of surgery could potentially disrupt the vocal cord intervention. Preoperative vocal cord dysfunction requires close observation during the periextubation period and can be addressed postoperatively. Patients with preoperative vocal cord dysfunction should be cautioned about the risk of postoperative bilateral vocal cord dysfunction, which would necessitate permanent tracheostomy.

Finally, the preoperative CT scan should be evaluated for evidence of bronchial or tracheal compression, which could complicate intubation and double-lumen ETT placement. If airway compression is suspected, close preprocedural discussion between surgeon and anesthesiologist is necessary before induction. ${ }^{14}$ If the TAAA distorts the left mainstem bronchus to a degree that placing a standard left-sided double-lumen ETT is not possible, then endotracheal intubation with a bronchial blocker advanced into the left mainstem bronchus would be the preferred approach. Using a rightsided double-lumen ETT runs the risk of occluding the right upper lobe and is not favored by our anesthesiology group. Lastly, if there is proximal airway difficulty, then awake fiberoptic single-lumen endotracheal intubation with placement of a left-sided bronchial blocker is advisable.

\section{Renal}

Postoperative acute kidney injury (AKI) after TAAAR is a major contributor to adverse outcomes. ${ }^{15}$ As expected, preoperative renal dysfunction strongly predicts morbidity and mortality after TAAAR. ${ }^{16,17}$ Chronic kidney disease (CKD), defined as a preoperative estimated glomerular filtration rate $<60 \mathrm{~mL} / \mathrm{min} / 1.73 \mathrm{~m}^{2}$, was found in almost $40 \%$ of patients undergoing extent II TAAAR. ${ }^{16}$ In this propensity-matched cohort, patients with CKD had a $14 \%$ chance of needing renal-replacement therapy (RRT).

For patients with advanced CKD (estimated glomerular filtration rate $<45 \mathrm{~mL} / \mathrm{min} / 1.73 \mathrm{~m}^{2}$ ), the risk of renal failure necessitating dialysis can be discussed to prepare the patient and family for that possibility. Preoperative nephrology consultation is advised for these patients. While advanced age and CKD are clear risk factors for the need for RRT, the greatest risk is in patients arriving with aortic rupture requiring emergency surgery. ${ }^{16}$

Patients with reduced creatinine clearance should receive adequate hydration before surgery or $\mathrm{CT}$ imaging to reduce the risk of AKI. If these patients require CT scanning or coronary angiography, then we also administer $\mathrm{N}$-acetylcysteine, which may be beneficial and poses little risk of side effects. ${ }^{18}$ Intraoperative strategies to reduce AKI include cold crystalloid perfusion, ${ }^{19}$ left heart bypass, ${ }^{20}$ and distal aortic perfusion. ${ }^{19,20}$ Nevertheless, no prophylactic therapy has been consistently shown to protect against the development of AKI. ${ }^{21}$

We do not consider preoperative end-stage renal disease to contraindicate TAAAR; approximately $2 \%$ of our 
patients are receiving RRT at the time of surgery. ${ }^{1}$ In our practice, during the past decade, 30 patients on dialysis have undergone TAAAR; these patients had 7\% 30-day mortality and $20 \%$ operative mortality. Such patients are counseled about the surgical risks and undergo a thorough cardiovascular workup because of the relatively high prevalence of cardiac comorbidities in that population.

\section{Hematologic and General}

Patients taking antiplatelet agents have $\mathrm{P}_{2} \mathrm{Y}_{12}$ inhibitors and aspirin stopped 9 days before TAAAR. All forms of antithrombotic therapy (warfarin and non-vitamin K oral anticoagulants [NOACs]) are also discontinued 9 days before surgery without bridging; however, in patients with mechanical heart valves who are being bridged with enoxaparin, this drug is stopped 2 days before surgery, which is consistent with bridging recommendations. ${ }^{22}$ Those with mechanical heart valves who require an urgent operation while receiving warfarin therapy are administered intravenous vitamin $\mathrm{K}$ preoperatively to reverse anticoagulation. ${ }^{23}$ In emergency cases, prothrombin complex concentrate (KCentra; CSL Behring, King of Prussia, Pa) is administered to reverse warfarin and NOAC anticoagulation. Recently, new medications have become available for rapid reversal of NOACs: idarucizumab (Praxbind; Boehringer Ingelheim, Ingeleheim am Rhein, Germany) for reversing dabigatran, and the factor $\mathrm{Xa}$ inhibitor reversal agent andexanet alfa (Andexxa; Portola Pharmaceuticals, South San Francisco, Calif) for reversing rivaroxaban and apixaban. We also enlist our colleagues in hematopathology and blood banking to guide us as needed regarding the rapid reversal of anticoagulants.

Age is an important indicator of overall physical reserve and risk. Even at high-volume centers, octogenarian patients are at significant risk (17\%-26\%) of operative mortality after TAAAR, ${ }^{24,25}$ especially extent II TAAAR (odds ratio, 11.6). ${ }^{25}$ Octogenarian patients, who represent about $6 \%$ of our TAAAR patients and $9 \%$ of the extent III and IV cohort, are more likely than younger patients to present with rupture or acute symptoms, leading to more adverse outcomes. Assessments for nutritional status ${ }^{26}$ and frailty, such as gait speed, are useful for identifying patients who may benefit from preoperative nutritional support or rehabilitation ("prehab") ${ }^{27}$ or who may not be surgical candidates at all. Finally, for patients with significant dementia, TAAAR is typically not advisable. In all of these situations, an informed discussion among the patient, family, and surgeon is required to balance the risks associated with surgery against the risks incurred by forgoing surgery.

\section{CONCLUSIONS}

In addition to surgical planning, the preoperative assessment of TAAAR patients requires careful evaluation of

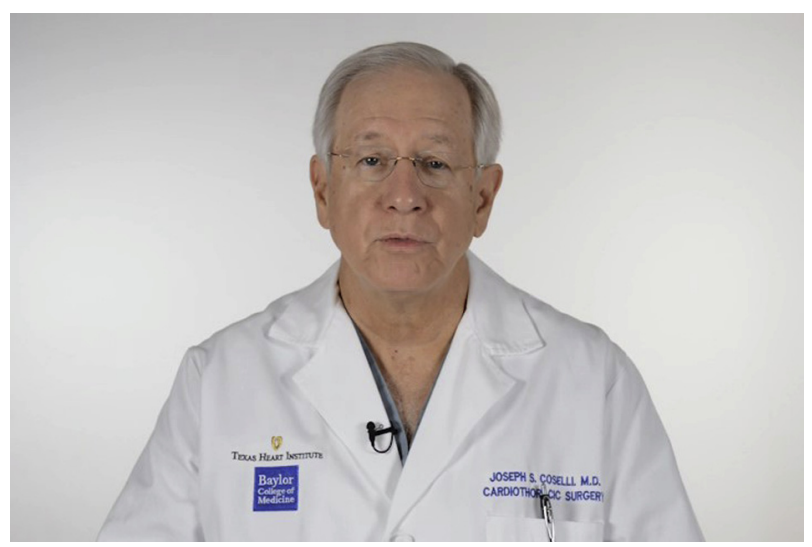

VIDEO 1. Dr Coselli highlighting the major preoperative considerations for thoracoabdominal aortic aneurysm repair. These include approaches to concomitant proximal aortic aneurysm, preoperative cardiac workup and management of coronary artery disease, and assessments made to determine whether a patient is a suitable candidate for surgery. Video available at: https://www.jtcvs.org/article/S0022-5223(20)30200-2/fulltext.

comorbidities to reduce the likelihood of adverse events and increase the likelihood of successful outcomes (Video 1).

\section{Conflict of Interest Statement}

All authors are in agreement regarding the content of the manuscript. Dr Coselli participates in clinical trials with Bolton Medical; provides consultation for and participates in clinical trials with Medtronic and W.L. Gore \& Associates; and provides consultation for, participates in clinical trials with, and receives royalties and grant support from Terumo Aortic. Dr LeMaire serves as an advisory panel member for Biom'up; serves as a consultant and a principal investigator for clinical studies sponsored by Terumo Aortic; and serves as a co-investigator for clinical studies sponsored by W.L. Gore \& Associates. Dr Preventza provides consultation for and participates in clinical trials with Medtronic and W.L. Gore \& Associates. All other authors have nothing to disclose with regard to commercial support. This work was not funded by a grant or any other source of external funding.

\section{References}

1. Coselli JS, LeMaire SA, Preventza O, de la Cruz KI, Cooley DA, Price MD, et al. Outcomes of 3309 thoracoabdominal aortic aneurysm repairs. J Thorac Cardiovasc Surg. 2016;151:1323-37.

2. Coselli JS, de la Cruz KI, Preventza O, LeMaire SA, Weldon SA. Extent II thoracoabdominal aortic aneurysm repair: how I do it. Semin Thorac Cardiovasc Surg. 2016;28:221-37.

3. MacArthur RG, Carter SA, Coselli JS, LeMaire SA. Organ protection during thoracoabdominal aortic surgery: rationale for a multimodality approach. Semin Cardiothorac Vasc Anesth. 2005;9:143-9.

4. Vranes M, Davidovic L, Vasic D, Radmili O. Coexistence of internal carotid artery stenosis in patients with abdominal aortic aneurysm. Korean Circ J. 2013;43: 550-6.

5. Chatterjee S, LeMaire SA, Green SY, Price MD, Amarasekara HS, Zhang Q, et al. Is incidental splenectomy during thoracoabdominal aortic aneurysm repair associated with reduced survival? J Thorac Cardiovasc Surg. September 9, 2019 [Epub ahead of print]. 
6. Coselli JS, Rosu C, Amarasekara HS, Green SY, Zhang Q, Price MD, et al. Reoperative surgery on the thoracoabdominal aorta. J Thorac Cardiovasc Surg. 2018;155:474-85.e1.

7. Fleisher LA, Fleischmann KE, Auerbach AD, Barnason SA, Beckman JA, Bozkurt B, et al. 2014 ACC/AHA guideline on perioperative cardiovascular evaluation and management of patients undergoing noncardiac surgery: a report of the American College of Cardiology/American Heart Association task force on practice guidelines. J Am Coll Cardiol. 2014;64:e77-137.

8. Girardi LN, Rabotnikov Y, Avgerinos DV. Preoperative percutaneous coronary intervention in patients undergoing open thoracoabdominal and descending thoracic aneurysm repair. J Thorac Cardiovasc Surg. 2014;147:163-8.

9. Jones MM, Akay M, Murariu D, LeMaire SA, Coselli JS. Safe aortic arch clamping in patients with patent internal thoracic artery grafts. Ann Thorac Surg. 2010; 89:e31-2.

10. van Diepen S, Norris CM, Zheng Y, Nagendran J, Graham MM, Gaete Ortega D, et al. Comparison of angiotensin-converting enzyme inhibitor and angiotensin receptor blocker management strategies before cardiac surgery: a pilot randomized controlled registry trial. J Am Heart Assoc. 2018;7:e009917.

11. Etz CD, Di Luozzo G, Bello R, Luehr M, Khan MZ, Bodian CA, et al. Pulmonary complications after descending thoracic and thoracoabdominal aortic aneurysm repair: predictors, prevention, and treatment. Ann Thorac Surg. 2007;83:S870-6; discussion S90-2.

12. Coselli JS, de la Cruz KI, Preventza O, LeMaire SA. Descending thoracic and thoracoabdominal aortic surgery. In: Sellke FW, Del Nido PJ, Swanson SJ, Abbott BG, eds. Sabiston \& Spencer Surgery of the Chest. 9th ed. Philadelphia: Elsevier; 2016:1184-213.

13. Girardi LN, Lau C, Munjal M, Elsayed M, Gambardella I, Ohmes LB, et al. Impact of preoperative pulmonary function on outcomes after open repair of descending and thoracoabdominal aortic aneurysms. J Thorac Cardiovasc Surg. 2017;153:S22-9.e2.

14. Anton JM, Herald KJ. Anesthetic management of open thoracoabdominal aortic aneurysm repair. Int Anesthesiol Clin. 2016;54:76-101.

15. Chatterjee S, LeMaire SA, Amarasekara HS, Green SY, Price MD, Yanoff MS, et al. Early-stage acute kidney injury adversely affects thoracoabdominal aortic aneurysm repair outcomes. Ann Thorac Surg. 2019;107:1720-6.
16. Coselli JS, Amarasekara HS, Zhang Q, Preventza O, de la Cruz KI, Chatterjee S, et al. The impact of preoperative chronic kidney disease on outcomes after Crawford extent II thoracoabdominal aortic aneurysm repairs. J Thorac Cardiovasc Surg. 2018;156:2053-64.e1.

17. Girardi LN, Ohmes LB, Lau C, Di Franco A, Gambardella I, Elsayed M, et al. Open repair of descending thoracic and thoracoabdominal aortic aneurysms in patients with preoperative renal failure. Eur J Cardiothorac Surg. 2017;51:971-7.

18. Kwok CS, Pang CL, Yeong JK, Loke YK. Measures used to treat contrastinduced nephropathy: overview of reviews. Br J Radiol. 2013;86:20120272.

19. LeMaire SA, Jones MM, Conklin LD, Carter SA, Criddell MD, Wang XL, et al. Randomized comparison of cold blood and cold crystalloid renal perfusion for renal protection during thoracoabdominal aortic aneurysm repair. J Vasc Surg. 2009;49:11-9; discussion 19 .

20. Bhamidipati CM, Coselli JS, LeMaire SA. Perfusion techniques for renal protection during thoracoabdominal aortic surgery. J Extra Corpor Technol. 2012;44: P31-7.

21. Sharma K, Slawski B. Renal disease and the surgical patient: minimizing the impact. Cleve Clin J Med. 2018;85:559-67.

22. Tan CW, Wall M, Rosengart TK, Ghanta RK. How to bridge? Management of anticoagulation in patients with mechanical heart valves undergoing noncardiac surgical procedures. J Thorac Cardiovasc Surg. 2019;158:200-3.

23. Garcia DA, Crowther MA. Reversal of warfarin: case-based practice recommendations. Circulation. 2012;125:2944-7.

24. Huynh TT, Miller CC III, Estrera AL, Porat EE, Safi HJ. Thoracoabdominal and descending thoracic aortic aneurysm surgery in patients aged 79 years or older. $J$ Vasc Surg. 2002;36:469-75.

25. Aftab M, Songdechakraiwut T, Green SY, Zarda S, Price MD, Nalty CC, et al. Contemporary outcomes of open thoracoabdominal aortic aneurysm repair in octogenarians. J Thorac Cardiovasc Surg. 2015;149:S134-41.

26. Hill A, Nesterova E, Lomivorotov V, Efremov S, Goetzenich A, Benstoem C, et al. Current evidence about nutrition support in cardiac surgery patientswhat do we know? Nutrients. 2018;10.

27. Arora RC, Brown CH IV, Sanjanwala RM, McKelvie R. "NEW" prehabilitation: a 3-way approach to improve postoperative survival and health-related quality of life in cardiac surgery patients. Can J Cardiol. 2018;34:839-49. 